lung der alkoholischen Lösungen von A. B. C. und D. mit concentrirtem Essig. Dabei ergab sich nun Folgendes:

A. und B. mit einem gleichen Volum concentrirten Essig versetzt, blieben vollkommen klar. C. und D. hingegen erschienen bei gleicher Behandlung sofort als ein trübes gelblickes Gemisch.

6) Diese, dem Zweck völlig entsprechende Prüfung des Chinoidins auf Pech-oder Colophongehalt kann man noch einfacher anstellen: Man zerreibt das Präparat mit Wasser, lässt es darin suspendiren und setzt die Säure hinzu; das ächte Präparat muss sich sofort ganz klar auflösen, wälrend ein mit Pech oder Colophon verfälschtes Chinoidin nur ein trübes Gemisch bildet.

Die physische Abweichung des vorgedachten Chinoidins von dem vorhandenen ächten, war also dieser Prüfung zufolge unwesentlich: es war in der herrschenden feuchten Luft oberfächlich deliquescirt und glänzend geworden, und hatte durch diese äussere Verschiedenheit die besondere Aufmerksamkeit erregt'.

\title{
Ueber den Gehalt der Gentianawurzel an Gallertsäure;
}

$$
\text { Denis. }
$$

(Auszug aus dem Journ. de Pharmacie XXII. 303.)

8 Unzen gröblich gepülverter Wurzeln von Gantiana lutea liess ich mit 8 Unzen Wasser aufweichen, weil ohne diese Vorsicht das Wassez sie nicht leicht durchdringt, die aufgeblähete Masse gab ich in ein schickliches Gefäss, und 
liess jedesmal wenig Wasser aufgiessen. Nach einigen Minuten floss eine dunkelbraune dickliche Flüssigkeit $a b$, nachdem 12 Unzen abgelaufen waren, wurde die Farbe heller, und nach Verwendung von 3 Kilogram. Wasser war die Wurzel geschmacklos. Nach 12 Stunden bildele die erste Flüssigkeit eine dicke Gallerte, ich gab sie anf Leinwand und wusch den Rïckstand mit kallem Wasser aus, um die löslichen Theile daraus zu entfernen. Der Riückstand war nun geschmacklos, löste sich leicht in kohlensaurem Kali, woraus er durch Alkohol, Zucker u. s. w. gefällt wurde, und verhielt sich wie Gallertsäure.

Ich liess nun noch, nach Braconnot, gepülverte mit kaltem Wasser erschöpfte Wurzeln mit alkalihaltigem Wasser auskochen, und versetzle die kolirten Flüssigkeiten mit einer sehr verdünnten Aullösung von Chlorcalcium, wodurch eine roluminöse und durchscheinende "Gallerle von gallertsaurem Kalk sich bildete, die mit salzsaurem Wasser ausgekocht wurde, um den Kalk und das SiärkmehI aufzulösen, worauf ich nach Auswaschen eine Gallerte bekam, die alle von Bracounot angegebenen Eigenschaften der Gallertsäure besass.

\section{Krapp.}

Runge unterscheidet im Krapp drei verschiedene Farbstoffe:

1) Krapppurpur. Ein krystallinisches orangerothes Pulver, welches in kochendem Alaunwasser, in Auflösungen von kaustischen und kohlensauren Nlkalien mit kirschrother Farbe auflöslich ist. Durch Schwefelsäure wird eine brillante rothe Farbe dadurch entwickelt. Es löst sich in Aether und Alkohol, und krystallisirt daraus. Seine Auflösung 